DOC ,

D 101,60/2:

1571

Research Report 1571

\title{
Predicting First-Run Gunnery Performance on Tank Table VIII
}

David A. Campshure and Eugene H. Drucker

Human Resources Research Organization

August 1990

Approved for public release; distribution is unlimited 